\title{
Student Veterans: Does How We Welcome Them Matter?
}

Lisa A. Giampaolo, Department of Higher Education Leadership, Maryville University of St. Louis

Frances D. Graham, Department of Higher Education Leadership, Maryville University of St. Louis

The recent influx of veterans into higher education has caused an increase of dedicated services and programs. Educational success is contingent upon student involvement in their educational communities, and orientation plays an important role in facilitating this engagement. Using quasiexperimental research design, and Schlossberg's constructs of mattering and marginality in higher education as a lens, this study sought to discover if student veterans experienced differing levels of mattering to their schools when categorized by the type of orientation they attended. Five hundred eighty-nine student veterans at 13 public universities within one Midwestern state completed the Unified Measure of University Mattering Instrument (France, 2011), and provided limited demographic information. Findings demonstrate that student veterans who experienced an orientation session which included a session designed exclusively for veterans demonstrated statistically significant higher scores in their perceived mattering to their school than student veterans who did not attend orientation. However, student veterans who attended standard orientation without veteranspecific content did not demonstrate statistically significant higher scores that those who did not attend orientation at all. Results indicate how small changes in traditional programs can have a significant impact on student veterans' sense of mattering to their university. 
Since the passage of the Servicemen's Readjustment Act of 1944 (SRA), the United States laid before its institutions of higher education the mandate to educate military service members and to help facilitate their transition from military careers into civilian society. Prior to the enactment of the SRA, land-grant institutions trained select groups of young men to enter the military as officers, but the new SRA mandate to retrain veterans leaving service solidified and greatly expanded the relationship between higher education and the military (Abrams, 1989). The millions of veterans who have attended colleges and universities using veterans' educational benefits since 1944 (Dortch, 2012) demonstrate this relationship.

Much research has been conducted and published that describes student veterans and their experiences on college and university campuses. While some researchers have focused on the overall experience of this transition from the student veterans' perspective (DiRamio et al., 2008; Kirchner et al., 2014), others have focused on the ways in which institutions can help facilitate the transition process for student veterans through courses, comprehensive services, and interventions (Furtek, 2012; Lange et al., 2016). However, only a few studies have specifically examined orientation programs in this context (Bagby et al., 2014; Darcy \& Powers, 2013; Ritz, Heggen et al., 2013; Witkowsky et al., 2016).

Institutions of higher education have addressed the need for orientation content that is specific to student veterans in several ways. Some have created stand-alone orientation programs for student veterans, others have supplemented existing orientation programs with veteranfocused break-out or add-on sessions (Jones, 2011; Ritz et al., 2013), and still others do not offer any veteran-specific content in their orientations. Understanding the impact of different types of orientation programs can help campus administrators make decisions about their institutions' orientation programs and how to best serve their student veteran population.

The primary research question explored in this study was the following: Are student veterans' perceptions of the degree to which they matter to their universities affected by the type (general or veteran- 
specific) of orientation they attend? The hypothesis was formulated as follows: student veterans who attended a student orientation program with veteran-specific content will report a statistically significant higher sense of mattering to their university than those who either did not attend student orientation or attended a regular student orientation without veteran-specific content.

\section{Literature Review}

\section{History of the Relationship of Higher Education and the Armed Forces}

The combination of the Morrill Land Grant Act of 1862 and the National Defense Act of 1916 established the initial relationship between the armed forces and higher education in the United States as one of training young men before they entered the military. The Morrill Act required military training to be offered as part of the curriculum, and the National Defense Act established the precursor to the Reserve Officer's Training Corps (ROTC).

The passage of the SRA changed the relationship between the military and higher education from one of training to re-training. The end of World War II saw the discharge of millions of service members, and in response, Congress passed the SRA to mitigate the potential negative impact such an influx could have on the economy (Hammond, 2017). The SRA provided veterans with financial benefits, including unemployment support, loans for housing and businesses, and access to postsecondary education (Rumann \& Hamrick, 2009). The educational benefits associated with the SRA became collectively known as the first GI Bill ${ }^{1}$.

Following the success of the SRA, the GI Bill has gone through several adaptations and modifications over the years, and the most recent version of the GI Bill, the Post-9/11 Veterans Educational Assistance Act of 2008, was signed into law on June 30, 2008. This sweeping new legislation reinvigorated the GI Bill and increased its value substantially (Martorell, \& Bergman, 2013). The most recent records published by the VA in 2015 show that nearly 800,000 veterans have used the Post-9/11 GI Bill,

1 GI Bill $($ is a registered trademark of the U.S. Department of Veterans Affairs. https://www.govinfo.gov/app /details/FR-2014-03-10/2014-05110 
resulting in payments of over $\$ 11$ billion (U.S. Department of Veterans Affairs, 2016).

Over the last 150 years, the relationship between the military and institutions of higher education has evolved. While many institutions continue to offer ROTC programs, the primary focus is now on retraining veterans. Successful fulfillment of this retraining mandate depends upon student veteran persistence to graduation. To more clearly understand the factors which influence degree attainment, it is imperative first to understand the divergent cultures of the military and academia.

\section{Military and Academic Cultures}

Researchers contend that military culture can be defined by its organizational structure, framework, and rules, which are understood through training and acculturation and are codified in the Uniform Code of Military Justice (Redmond et al., 2015). The hierarchical nature of the military is central to its culture and stands in stark contrast to the prevalent culture of traditional higher education. The military's distinct culture warrants recognition and requires the use of multicultural competencies developed by the members of the Association for Multicultural Counseling and Development and endorsed by the American Counseling Association (Fenell, 2008). Fenell (2008) asserts that failure to recognize the complex influence of military culture, in addition to any other cultural identities that military personnel and veterans have, can have a negative impact on the counseling relationship. Similarly, professionals in higher education must also recognize and adopt these multicultural competencies in their practices.

Student veterans bring with them a culture that values self-sacrifice and group security over individual well-being or advancement. To illustrate this point, Ryan et al. write, "Acts of self-discipline, respect for authority and the chain of command, minimized individual expression, and unquestioned deference to individuals of higher rank are just some of the practices held in high regard in the military culture" (2011, p. 57). By contrast, they describe academic culture as person-centered and focused on individual accomplishment, suggesting that higher education "encourages students to celebrate their individuality and discover 
qualities that distinguish them from their peers" (Ryan et al., 2011, p. 57). Student veterans who are acculturated to follow set procedures and to obey clearly defined lines of command may find themselves challenged by the apparently amorphous nature of life in higher education.

The dichotomy between military culture and academic culture may challenge student veterans and lead to stress as they attempt to transition from one cultural reality to another (Livingston et al., 2011; Rumann \& Hamrick, 2010). Vacchi (2012) describes the college campus as being an awkward environment for veterans because its culture is so different from their military experience that they feel out of place and understand little of how to navigate the new culture. He explains that the difficulty some veterans have reaching out for assistance is related to a primary tenet of military culture which discourages admitting weakness and seeking help. He asserts that this is the primary reason many challenges experienced by veterans, such as anxiety, alcohol and drug addiction, as well as other medical conditions, go undiagnosed (Vacchi, 2012). Because veterans are not inclined to seek out assistance, it is the responsibility of faculty and staff members who work with the student veteran population to ensure that their needs are met. Designing programs that bridge the gap between military culture and higher educational norms and practices is essential for student veterans to successfully transition into higher education.

\section{Transitional and Ongoing Support Services for Student Veterans}

The experiences of military personnel as they transition to becoming students on college campuses have begun to attract more attention. Utilizing Transition Theory (Schlossberg, 1984) the researchers DiRamio et al. (2008) published a widely cited article that describes the transition experiences of 25 male and female veterans at three universities. In this article the authors describe the three phases of moving in, moving through, and moving out of the military, and also describe the beginning phase of moving into higher education. Within each transitional phase, themes that emerged from their research are discussed. Understanding these themes, which are related to the challenges and stressors faced by veterans moving into institutions of higher education, can be especially 
helpful for higher educational professionals who design interventions, support services, and orientation programs.

As veterans transition into higher education, new concerns arise for them regarding their ability to relate to other students, their capacity to not seem too different from other students, their financial stability for themselves and their dependents, and their need for specialized support relating to education benefits, disabilities, and mental health (DiRamio et al., 2008). By identifying these themes in the transition experiences of student veterans, the researchers significantly advanced the understanding of this population, and provided a strong foundation on which other researchers and school administrators could build.

A more recent study (Williams-Klotz \& Gansemer-Topf, 2017) surveyed a larger population of student veterans to elucidate the challenges student veterans face as they transition into higher education. In that study, which collected qualitative data from 355 student veterans in attendance at 13 two-year and four-year institutions in Iowa, the researchers were able to add to the descriptive work begun by others and to produce results that supported previous findings. They were also better able to capture the universality of student veteran experiences by using a larger sample and by diversifying the type of institutions sampled.

Williams-Klotz and Gansemer-Topf (2017) provide recommendations to improve practices to target the transitional challenges and impediments that impact student veterans, including recommendations directly related to student orientation. They urge schools to increase the amount of information disseminated to student veterans through in-processing and student veteran orientation programming (2017, p. 95).

Using the concept of mattering and marginality in higher education (Schlossberg, 1989) as a lens to interpret responses from an 11-student focus group, researchers at Rhode Island College were able to explore and describe the transitional experiences of student veterans (Darcy et al., 2018). When the authors parsed veterans' comments from two focus groups into categories, they found that they aligned well with the constructs of mattering and marginality described by Schlossberg. They found common ways in which their students experienced mattering 
related to the constructs of dependence, appreciation, and attention. Conversely they described comments which reflected a sense of marginality related to the constructs of importance and ego-extension. By using Schlossberg's work as a theoretical construct, Darcy et al. (2018) opened a valuable line of inquiry into how student veterans experience a sense of mattering or of marginality on campus, and provided a helpful way for professionals who work with student veterans to discuss the student veteran experience on campus. The researchers advised tailoring programs and practices to emphasize a sense of mattering to support a campus climate of connection and involvement.

If a healthy sense of mattering is essential for student involvement and subsequent student success, then student affairs practitioners should investigate how various programs impact students' perceived sense of mattering or marginality. Because orientation programs are often students' first formal introduction to an institution, it is especially critical to understand their potential impact.

\section{Orientation-Facilitated Transitions}

While the length and content of student orientation programs can vary by institution, there are national networks that are dedicated to sharing information and to improving these programs. In 2010, The National Resource Center for The First-Year Experience and Students in Transition and The National Orientation Directors Association published a best-practices guide for student orientation programs, which asserts that student veterans, like other diverse student populations, require specialized orientation programs (Ward-Roof, 2010). Similarly, specifically focused on the experience of student veterans in higher education, researchers advocate for specialized orientation programs for the population (Kelley et al., 2013; Kirchner et al., 2014; Kirchner, 2015; O’Herrin, 2011; Vacchi \& Berger, 2014).

Beginning with the seminal work of Pascarella, Terenzini, and Wolfe (1986), much has been written about the importance of orientation programs. Orientation programs connect new students with their peers, staff, and faculty and facilitate their initial connection to the institution. 
(Mayhew et al., 2010; Williford et al., 2000).

Student veteran-focused orientation is not a new concept. It is fascinating to look back at an article published in the Journal of Higher Education in 1949, where Wilkinson stressed the importance of orientation for the student veterans of World War II asserting, "This transition must not be left to chance" (1949, p. 472). Nearly seven decades ago, professionals already recognized the importance of programs to aid veterans' transition to higher education, and this remains true today. Vacchi's Model of Student Veteran Support includes orientation as a significant mechanism in transition support (Vacchi et al., 2017). And while it appears clear from anecdotal evidence that orientation programs tailored specifically for student veterans can be worthwhile, study of the impact of orientation programs on student veterans is only beginning to emerge in the literature.

More recent research gives us a clearer picture of student veterans on campus and programs designed for them, which may correlate with improved retention and other measures of student success (Bagby et al., 2014; Ritz et al., 2013; Witkowsky et al., 2016). Researchers at Ball State University found that during students' first semester, veterans who attended student veteran-focused orientation had higher average GPAs, higher credit hour completion rates, and a higher second semester retention rate when compared to other veterans who did not attend the student veteran-focused orientation (Ritz, et al., 2013). Witkowsky et al. (2016) compared student veterans' and non-veterans' orientation program experiences and found that while student veterans rated their overall experience higher than non-veterans, they also reported feeling much less connected to and welcomed by the campus.

To understand how and why student orientation programs may affect the student veteran population, much more work must be done. It is essential to understand the underlying social constructs that influence student veterans' perceptions of their orientation programs. If such programs are to positively influence student veterans' perceptions of their institutions and their own place within them, schools must design orientation programs that can help student veterans feel that they matter. 


\section{Research Design}

The primary purpose of this study was to investigate whether there is any discernible association between a student veteran's sense of mattering or marginality to their school, and the type of student orientation program attended (general or veteran-specific). This study adopted a critical quantitative research design with quasi-experimental methodology because this allowed the researcher to examine possible relationships between dependent and independent variables without being able to control the randomization of group assignment or to account for all possible confounding variables.

The researcher collected anonymous quantitative survey data from student veterans actively enrolled at any of the 13 public, fouryear universities located in one Midwestern state. As shown in Table 1, the schools represented five diverse Carnegie Classifications (Carnegie Foundation, 2011). For the purpose of this study, a student veteran was defined as "any student who is a current or former member of the activeduty military, the National Guard, or Reserves regardless of deployment status, combat experience, legal veteran status, or GI Bill," as defined by Vacchi (2012, p. 17). Active enrollment was defined as being enrolled for at least one credit at any one of the 13 universities sampled.

\section{Table 1}

\section{Carnegie Classification of Institutions of Higher Education}

\begin{tabular}{|lc|}
\hline Basic Carnegie Classification & $\begin{array}{c}\text { Number of Schools } \\
\text { in Sample }\end{array}$ \\
\hline B1- Baccalaureate Colleges & 2 \\
M1- Master's Colleges \& Universities: Larger Programs & 5 \\
M2- Master's Colleges \& Universities: Medium Programs & 2 \\
M3- Master's Colleges \& Universities: Small Programs & 2 \\
R1- Doctoral Universities: Highest Research Activity & 2 \\
\hline
\end{tabular}


As shown in Table 2, the survey collected limited demographic information (age, gender, institution attended, and degree sought) from respondents, as well as the type of orientation they attended and a measure of their sense of mattering to their school. The instrument chosen for this purpose was the Unified Measure of University Mattering Scale (France, 2011). Initially developed and published by France and Finney (2010) as the University Mattering Scale, France (2011) later revised the instrument from 24 to 15 questions and renamed the pareddown instrument the UMUM. France demonstrated reliable psychometric properties of the UMUM across four independent samples and also established construct validity by using the known-groups method comparing scores of transfer and native students.

\section{Table 2}

\section{Respondent Demographics}

\begin{tabular}{|c|c|c|}
\hline Characteristic & $\mathrm{n}$. & $\%$ \\
\hline \multicolumn{3}{|l|}{ Gender Identity } \\
\hline Female & 200 & $34.0 \%$ \\
\hline Male & 379 & $64.3 \%$ \\
\hline Transgender & 4 & $0.7 \%$ \\
\hline Preferred not to respond & 6 & $1.0 \%$ \\
\hline \multicolumn{3}{|l|}{ Age } \\
\hline $18-22$ & 154 & $26.1 \%$ \\
\hline $23-29$ & 192 & $32.6 \%$ \\
\hline $30-39$ & 156 & $26.5 \%$ \\
\hline $40-49$ & 57 & $9.7 \%$ \\
\hline $50+$ & 30 & $5.1 \%$ \\
\hline \multicolumn{3}{|l|}{ Academic Level } \\
\hline Graduate & 232 & $20.5 \%$ \\
\hline Undergraduate & 468 & $79.5 \%$ \\
\hline \multicolumn{3}{|l|}{ University } \\
\hline \# 1 & 30 & $5.1 \%$ \\
\hline$\# 2$ & 39 & $6.6 \%$ \\
\hline \# 3 & 23 & $3.9 \%$ \\
\hline \# 4 & 74 & $12.6 \%$ \\
\hline
\end{tabular}




$\begin{array}{lll}\text { \# } 5 & 103 & 17.5 \% \\ \# 6 & 78 & 13.2 \% \\ \# 7 & 55 & 9.3 \% \\ \# 8 & 30 & 5.1 \% \\ \# 9 & 24 & 4.1 \% \\ \# 10 & 45 & 7.6 \% \\ \# 11 & 31 & 5.3 \% \\ \# 12 & 22 & 3.7 \% \\ \# 13 & 35 & 5.9 \%\end{array}$

Electronic survey links were distributed via email from local campus veteran services professionals to student veterans at each of the 13 study institutions. The respondents were incentivized to participate in the study by entering into a randomized drawing for a $\$ 250$ gift card through an option to submit an electronic entry form provided at the end of the survey. Survey completion, however, was not required to enter the drawing. All data for the gift card drawing were kept separate from the research survey data, and identifying information was not collected for the research survey. In all, 693 surveys and drawing entries were logged, and a total of 589 completed surveys were collected and analyzed.

\section{Results}

Statistical analyses were conducted comparing the dependent variable, scores on the UMUM, for three different groups of student veterans, who were defined by the independent variable, type of student orientation experienced (Groups A, B, and C). Group A did not attend student orientation, and Groups B and C did attend different types of student orientation. Group B attended a standard student orientation which did not include any veteran-specific information, while Group C attended an orientation which included the opportunity to participate in at least one break-out or add-on session exclusively for student veterans.

A Welch's ANOVA F-test was used rather than the standard ANOVA F-test because the assumption of the homogeneity of variance was not met, as measured by Levene's Statistic. Table 3 displays the results for 
Levene's Test of Homogeneity of Variances. The Welch's adjusted F-ratio was calculated as $F(2,196)=3.69(p<.05)$.

\section{Table 3}

\section{Test for Homogeneity of Variances}

\begin{tabular}{|llllr|}
\hline UMUM Score & Levene Statistic & df1 & df2 & Sig. \\
\hline Based on mean & 4.368 & 2 & 586 & .013 \\
Based on median & 3.792 & 2 & 586 & .023 \\
Based on median with adj df & 3.792 & 2 & 566 & .023 \\
Based on trimmed mean & 4.204 & 2 & 586 & .015 \\
\hline
\end{tabular}

The descriptive statistics derived from Welch's F-test are displayed in Table 4 for the three comparison groups. This analysis revealed that Group B ( $\mathrm{m}=61.14$, sd = 12) did not have significantly different UMUM scores than Group A ( $m=59.45, \mathrm{sd}=14)$. However, there was a significant difference in UMUM scores between Group C $(\mathrm{m}=64.00$, $\mathrm{sd}=11)$ and Group A.

\section{Table 4}

\section{Unified Measure of University Mattering Score}

\begin{tabular}{|llll|}
\hline Group & N & Mean & Std. Deviation \\
\hline Group A (no orientation) & 191 & 59.45 & 14.230 \\
Group B (regular orientation) & 327 & 61.14 & 12.292 \\
Group C (orientation with & 71 & 64.00 & 11.092 \\
veteran-specific content) & & & \\
\hline
\end{tabular}

A Games-Howell post hoc test was then used to create pairwise comparisons (Table 5). The difference between the means of Groups A and $B$ was $\pm 1.690, p>.05$, which indicates that, while members of Group A scored slightly higher than those of Group B, the difference between the means was not significant. There was also no significant observable difference between the means of Groups B and C, $\pm 2.859, \mathrm{p}>.05$. By contrast, the difference between the means of Groups $A$ and $C$ was significant, $\pm 4.550, \mathrm{p}<.05$. 


\section{Table 5}

\section{Games-Howell Pairwise Comparison}

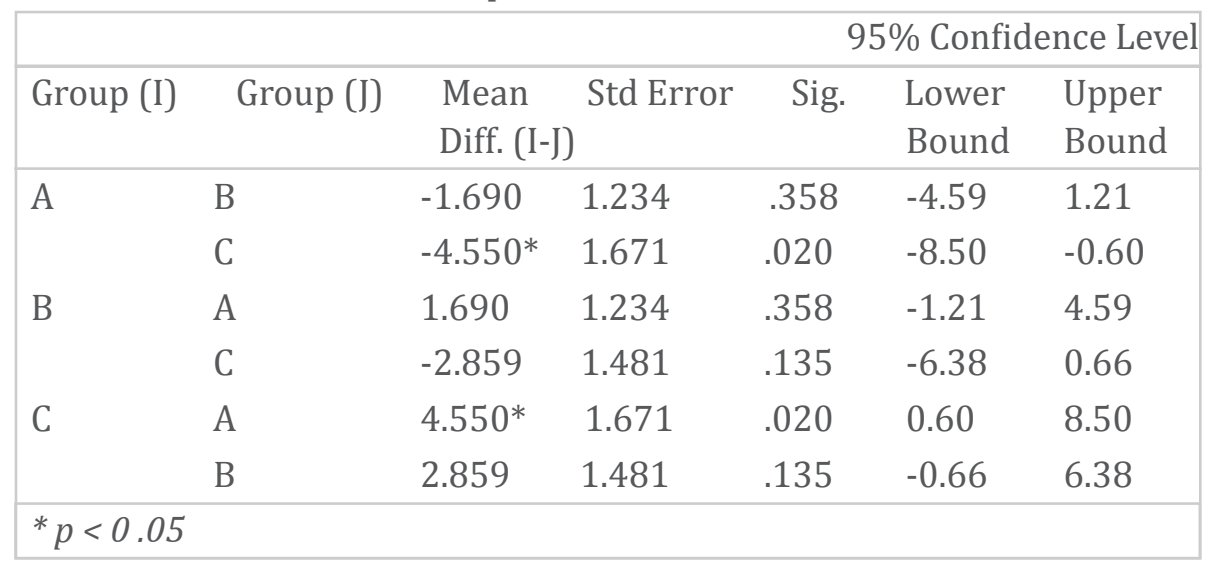

Only the group who attended an orientation with veteran-specific content (Group C) had a mean score that was significantly higher than the group who did not attend orientation (Group A). The group who attended an orientation without veteran-specific content (Group B) did not.

\section{Discussion}

This study investigated whether there was an increased sense of mattering for student veterans who attended a student orientation that contained veteran-specific content. Using the quasi-experimental design of this study as a lens for interpreting the data produced, we can consider UMUM scores for Group A as a quasi-control group, students who did not experience either type of tested treatment. By contrast, Groups B and C experienced two different treatments. We could interpret the difference in UMUM scores between the treatment groups and the control group, as potentially indicating treatment effects.

Student veterans who attended an orientation session with veteranspecific content (Group C) reported a statistically significant increase in their sense of mattering to their school over student veterans who did not attend any orientation session (Group A), allowing us to assert a positive relationship between a student veteran-specific orientation experience with an increased sense of mattering to their school for the student veterans who were surveyed. The same cannot be asserted for 
student veterans who attended a regular orientation session (Group B) because they did not score significantly higher than student veterans who did not attend any orientation session at all (Group A). Of the two types of orientation sessions experienced by student veterans in this study, only an orientation session which included break-out or add-on veteran-specific content correlated positively to increased scores on the UMUM.

Thus, the research hypothesis should be accepted as stated: student veterans who attended a student orientation program with veteranspecific content will report a higher sense of mattering to their university than those who either did not attend student orientation or attended a regular student orientation without veteran-specific content.

\section{Limitations and Suggestions for Further Research}

This study included student veterans who were actively enrolled at any of 13 four-year universities in a Midwestern state, and while the institutions sampled represented diverse Carnegie Classifications (Carnegie Foundation, 2011), they were all public schools in one state. It would be desirable to increase the types of institutions sampled to include both private and proprietary schools. It would also be advantageous to vary the location of the samples to include a more representative crosssection of the United States. Due to the quasi-experimental design of the study, it is important to remember that group membership was not randomly assigned. It is also important to recognize that the responses from individual schools varied greatly in number and it is possible that one school's exceptionally delivered orientation program or another school's less-effective program may have skewed the results of this study.

The timing of the distribution of the survey may also have had an impact on the findings. In an effort to include responses from veterans who experienced general orientations prior to the system-wide adoption of veteran-focused orientation programming, the survey was distributed to all student veterans at one time. This meant that the time gap between experiencing their orientation and completing the survey could vary between a few days and a couple of years. For some respondents, there may have been a large time gap between their orientation session, and the survey date. Time and other factors may have influenced how they 
remembered their experience of orientation.

It would be interesting to perform a longer-term study to determine whether student veterans who experienced an orientation that included student veteran-specific break-out or add-on sessions had increased success in school. Other questions to be asked might include: Do student veterans who attend veteran-focused orientation sessions utilize veteran center resources more often than those who attended regular student orientations? Are there any differences in persistence or graduation that are correlated with beginning school with a veteran-focused student orientation program? If we can address some of these questions, we may begin to understand just how vital it is to provide orientation sessions which address the unique needs of the student veterans and to help the population feel that they matter to their schools.

\section{Conclusion}

The positive relationship that was found suggests that designing an orientation for student veterans which validates their experience as veterans is a worthwhile endeavor. The simple addition of veteran-specific content during regular orientation sessions can help an institution ease student veterans' transition to school and contribute positively to their sense of mattering to their school.

It is encouraging to note that the orientation sessions that were held at the schools sampled only added a break-out or add-on session for student veterans and did not significantly alter the delivery of student orientation. This may be a significant factor for implementing this type of orientation on any campus, because the cost of adding one or a small number of break-out sessions should be relatively low and may ultimately support student veteran success.

By thoughtfully evaluating orientation sessions using Schlossberg's (1989) construct of mattering and marginality, we can design programs that help student veterans feel more like they matter to their schools. Orientation sessions can be used to positively set the stage for an institution to build supportive and strong communities of learners who matter to each other and foster success. Schlossberg wrote simply, 
"institutions need to act as though each student matters," (Schlossberg et al., 1989, p. 58). 


\section{References}

Abrams, R. M. (1989). The U.S. military and higher education: A brief history. The Annals of the American Academy of Political and Social Science, 502, 15-28. Retrieved from http://www.jstor.org/ stable/1046973

Bagby, J., Barnard-Brak, L., Baggett, A., Sulak, T., Walter, M., \& Ragan, K. (2014). Student veteran transitions from combat to college: A nationwide analysis. The Journal of College Orientation and Transition, 22(1), 20-35.

Carnegie Foundation for the Advancement of Teaching (2011). The Carnegie Classification of Institutions of Higher Education, 2010 edition, Menlo Park, CA: Author.

Darcy, M., \& Powers, J. T. (2013). Student veterans: Advantages and obstacles in college transition. The Journal of College Orientation and Transition, 21(1), 55-64.

Darcy, M. G., Swagger, R., \& Cordeiro Ferreira, M. (2018). Student veterans on campus - next steps in program development. Journal of Military and Government Counseling, 6(1), 1-19.

DiRamio, D., Ackerman, R., \& Mitchell, R. L. (2008). From combat to campus: Voices of student-veterans. NASPA Journal, 45, 73-102. Retrieved from http://publications. naspa.org/naspajournal/vol45/ iss1/art5/

Fenell, D. L. (2008). A distinct culture. Counseling Today, 50, 8-35.

France, M. K. (2011). Introducing the unified measure of university mattering: Instrument development and evidence of the structural integrity of scores for transfer and native students. (Doctoral dissertation, James Madison University). Retrieved from https:// commons.lib.jmu.edu/diss201019/63/

France, M. K., \& Finney, S. J. (2010). Conceptualization and utility of university mattering: A construct validity study. Measurement \& Evaluation in Counseling \& Development, 43(1), 48-65. doi:10.1177/0748175610362369

Furtek, D. (2012). Developing a new transition course for military service members in higher education. College and University, 87(4), 33-36. 
Retrieved from https://search-proquest-com.proxy.library.maryville. edu/docview / 1079889025?accountid=40561

Hammond, S. (2017). Student Veterans in Higher Education: A Conversation Six Decades in the Making. In K. Eagan, L. McBain, \& K. Jones (Eds.), Student veteran data in higher education (New Directions for Institutional Research, no. 171, pp. 11-21). San Francisco, CA: Jossey-Bass, Inc. doi:10.1002/ir.20191

Jones, M. C. (2011). From war zones to classrooms: student-veterans' perspectives on transition. The Journal of College Orientation and Transition, 18(2), 20-32.

Kelley, B. C., Fox, E. L., \& Smith, J. M. (2013). Preparing Your Campus for Veterans' Success: An Integrated Approach to Facilitating the Transition and Persistence of Our Military Students. Sterling, Virginia: Stylus Publishing. Retrieved from http://search.ebscohost.com/login.

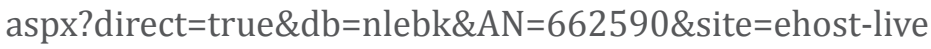

Kirchner, M. J. (2015). Supporting student veteran transition to college and academic success. Adult Learning, 26(3), 116-123. doi:10.1177/1045159515583813

Kirchner, M. J., Coryell, L., \& Yelich Biniecki, S. M. (2014). Promising practices for engaging student veterans. Quality Approaches in Higher Education, 5(1), 12-18. Retrieved from http://asq.org/edu/2014/09/ promising-practices-for-engaging-student-veterans.pdf

Lange, D. D., Sears, S. H., \& Osborne, N. J. (2016). Comprehensive services tailored for the transitional success of veterans in higher education. Journal of Postsecondary Education \& Disability, 29(3), 277-283. Retrieved from https://files.eric.ed.gov/ fulltext/EJ1123807.pdf Livingston, W. G., Havice, P. A., Cawthon, T. W., \& Fleming, D. S. (2011). Coming home: Student veterans' articulation of college re-enrollment. Journal of Student Affairs Research and Practice, 48(3), 315-331. Martorell, P., \& Bergman, P. (2013). Understanding the Cost and Quality of Military-Related Education Benefit Programs. Retrieved from http://www.jstor.org/ stable/10.7249/ j.ctt5vjwnk doi:10.7249/j. ctt5vjwnk.14 
Mayhew, M. J., Vanderlinden, K., \& Kim, E. K. (2010). A multi-level assessment of the impact of orientation programs on student learning. Research in Higher Education, 51(4), 320-345. doi:10.1007/ s11162-009-9159-2

O'Herrin, E. (2011). Enhancing veteran success in higher education. Peer Review, 13(1), 15-18. Retrieved from http://search.ebscohost.com/ login. aspx direct $=$ true $\& d b=e h h \& A N=60071933 \&$ site $=$ ehost-live Pascarella, E., Terenzini, P., \& Wolfe, L. (1986). Orientation to college and freshman year persistence/withdrawal decisions. Journal of Higher Education, 57(2), 155 - 175. doi:10.2307/1981479.

Redmond, S. A., Wilcox, S. L., Campbell, S., Kim, A., Finney, K., Barr, K., \& Hassan, A. M. (2015). A brief introduction to the military workplace culture. Work, 50(1), 9. doi:10.3233/WOR-141987

Ritz, G., Heggen, A., Ericson, K., \& Harris, J. (2016). Transition programs for student veterans. The Journal of College Orientation and Transition, 21(1), 65-78.

Rumann, C. B., \& Hamrick, F. A. (2009). Supporting student veterans in transition. In R. Ackerman \& D. DiRamio (Eds.), Creating a veteran friendly campus: Strategies for transition success (New Directions for Student Services, no. 126, pp. 25-34). San Francisco, CA: Jossey-Bass, Inc. doi:10.1002/ss.313

Rumann, C. B., \& Hamrick, F. A. (2010). Student veterans in transition: Reenrolling after war zone deployments. Journal of Higher Education, 81(4), 431-458.

Ryan, S. W., Carlstrom, A. H., Hughey, K. F., \& Harris, B. S. (2011). From Boots to Books: Applying Schlossberg's Model to Transitioning American Veterans. NACADA Journal, 31(1), 55-63.

Schlossberg, N. K. (1984). Counseling adults in transition. New York: Springer.

Schlossberg, N. K. (1989). Marginality and mattering: Key issues in building community. In D. Roberts, (Ed.), Designing campus activities to foster a sense of community (New Directions for Student Services, no. 48, pp. 5-15). San Francisco, CA: Jossey-Bass, Inc. doi:10.1002/ ss.371198948 
Schlossberg, N. K., Lynch, A. Q., \& Chickering, A. W. (1989). Improving Higher Education Environments for Adults: Responsive Programs and Services from Entry to Departure. San Francisco, CA: Jossey-Bass, Inc. U.S. Department of Veterans Affairs. (2016). FY 2015 Annual Benefits Report. Retrieved from https://benefits.va.gov/REPORTS/abr/ABREducation-FY15-02032016.pdf

Vacchi, D. (2012). Considering student veterans on the twenty-firstcentury college campus. About Campus, 17(2), 15-21. doi:10.1002/ abc. 21075

Vacchi, D. (2018). Understanding progress toward degree completion for student veterans in the post 9-11 era: A focused life narrative. (Doctor of Philosophy Dissertation), University of Massachusetts Amherst, Retrieved from https://scholarworks.umass.edu/ dissertations_ 2/1301?utm_source=scholarworks.umass. edu\%2Fdissertations_2\%2F1301\&utm_medium=PDF\&utm_ campaign=PDFCoverPages (1301)

Vacchi, D., \& Berger, J. B. (2014). Student veterans in higher education. In M. Paulsen (Ed.), Higher Education: Handbook of Theory \& Research (Kindle ed., Vol. 29). Dordrecht: Springer.

Vacchi, D., Hammond, S., \& Diamond, A. (2017). Conceptual Models of Student Veteran College Experiences. In K. Eagan, L. McBain, \& K. Jones (Eds.), Student veteran data in higher education (New Directions for Institutional Research, no. 171, pp. 11-21). San Francisco, CA: Jossey-Bass, Inc. doi:10.1002/ir.20192

Ward-Roof, J. A. (2010). Designing successful transitions: A guide for orienting students to college (Monograph No. 13, 3rd ed.). Columbia, SC: University of South Carolina, National Resource Center for The First-Year Experience and Students in Transition. Retrieved from http://search.ebscohost.com/login.aspx?direct= true\&db=eric \&AN=ED558878\&site=ehost-live

Wilkinson, G. E. (1949). Orientation Interview for Veterans. Journal of Higher Education, 20(9), 469-472. 
Williams-Klotz, D. N., \& Gansemer-Topf, A. M. (2017). Identifying the camouflage: Uncovering and supporting the transition experiences of military and veteran students. Journal of The First-Year Experience \& Students in Transition, 29(1), 83-98.

Williford, A. M., Cross Chapman, L., \& Kahrig, T. (2000). The university experience course: A longitudinal study of student performance, retention, and graduation. Journal of College Student Retention, 2(4), 327-340. Retrieved from https://search-proquest-com.proxy.library. maryville.edu/docview/ 196715006?accountid=40561

Witkowsky, P., Kumm, C., Mendez, S., Nicholson, H., Dimandja, O. O., \& Morris, P. (2016). Comparing military-connected and non-militaryconnected students' orientation experiences. The Journal of College Orientation and Transition, 24(1), 78-83. 